\title{
The first record of Gobichelifer chelanops (Pseudoscorpiones: Cheliferidae) from Iran
}

\author{
Mahrad Nassirkhani $^{1 *} \&$ Haji Mohammad Takalloo zadeh ${ }^{2}$ \\ ${ }^{1}$ Department of Entomology, Islamic Azad University, Arak, Iran \\ ${ }^{2}$ Department of Plant Protection, Faculty of agriculture, Shahid Bahonar University of Kerman, Kerman, Iran \\ *Corresponding author.E-mail: greenartificialturfgrass@gmail.com
}

\begin{abstract}
Gobichelifer chelanops Redikorzev is widely distributed throughout Central Asia. We report on new specimens attributed to this species collected from tree bark habitats in Iran.

Key words - Arachnida, Pseudoscorpiones, Cheliferidae, Gobichelifer chelanops, Iran, Kerman Province, biogeography
\end{abstract}

\section{Introduction}

Pseudoscorpions are small, yet abundant Arachnids found in most terrestrial ecosystems of the world. The first pseudoscorpion reported from Iran, Chelifer spinipalpis Redikorzev 1918, now placed in the genus Strobilochelifer, was described from Bazman, south-eastern Iran (Redikorzev 1918).

The most substantial contributions were made by Beier $(1951,1971)$. There are currently nine families, 21 genera and 39 species known from the country (Harvey 2011).

As part of a research program investigating the pseudoscorpion fauna of the region, we found specimens attributable to the cheliferid genus Gobichelifer Krumpál 1979. Although this genus is known from Central Asia and Mongolia (Krumpál 1979, Dashdamirov \& Schawaller 1995, Harvey 2011), there are no previous records from Iran. This paper is the result of our study on these specimens.

\section{Methods}

The material used in this study was collected from various geographical parts of Kerman Province, south-eastern Iran. The specimens were collected directly from under tree bark by using thin needles or extracted with Berlese funnels.

All specimens were preserved in $70 \%$ ethanol and were prepared for study as follows. The pedipalps, chelicera, first and fourth legs were dissected using thin needles, cleared with $60 \%$ lactic acid, and mounted on glass microscope slides in Hoyer's medium (a mixture of distilled water, chloral hydrate, Arabic gum and glycerin). The duration of the clearing phase was dependent on the degree of sclerotization of the body. The specimens were examined and illustrated with an Olympus BH-2 compound microscope and drawing tube attachment. The specimens are lodged in Collection of the Acarology Laboratory, Shahid Bahonar University of
Kerman, Iran.

Morphological terminology follows Chamberlin (1931), Harvey (1992) and Judson (2007). The following trichobothrial abbreviations were employed: $b=$ basal; $e b$ $=$ external basal; es $b=$ external sub-basal; $i b=$ internal basal; $i s b=$ internal sub-basal; ist $=$ internal sub-terminal; $e s t=$ external sub-terminal; $i t=$ internal terminal; $e t=$ external terminal; $t=$ terminal; $s b=$ sub-basal; $s t=$ sub-terminal. In addition, the following abbreviations are used: $\mathrm{mm}=$ millimeter; $\mathrm{L}=$ length; $\mathrm{W}=$ width $\mathrm{H}=$ height .

\section{Family Cheliferidae \\ Genus Gobichelifer Krumpál 1979 \\ Gobichelifer chelanops (Redikorzev 1922)}

Chelifer chelanops Redikorzev 1922: 267-270, figs. 9-11; Caporiacco 1935: 243.

Chelifer semenovi Redikorzev 1934: 430-432, figs. 8-10; Roewer 1936: fig. 66d (synonymized by Schawaller 1989: 26).

Gobichelifer dashdorzhi Krumpál 1979: 668-671, figs. 1-12; Okali 1988: 255 (synonymized by Schawaller 1986: 11).

Gobichelifer semenovi (Redikorzev): Schawaller 1986: 11-12, figs. 29-30; Beron 2002: 37.

Gobichelifer chelanops (Redikorzev): Schawaller 1989: 26, figs. 57-62; Harvey 1991: 502; Dashdamirov \& Schawaller 1995: 21-23, figs. 22-24, 87-90; Schawaller 1995: 126; Beron 2000: 173; Beron 2002: 39.

Material examined. Iran: Kerman Province: $350^{\lambda}, 50$ 우, $30^{\circ} 20^{\prime} 44^{\prime \prime} \mathrm{N}, 57^{\circ} 27^{\prime} 46^{\prime \prime} \mathrm{E} ; 13$ 子’ $^{\circ}, 18$ 우, $28^{\circ} 52^{\prime} 45^{\prime \prime} \mathrm{N}, 56^{\circ} 23^{\prime} 56^{\prime \prime}$

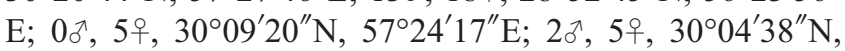
$56^{\circ} 39^{\prime} 25^{\prime \prime} \mathrm{E} ; 80^{\top}, 25$ 우, 31 $33^{\circ} 12^{\prime \prime} \mathrm{N}, 55^{\circ} 39^{\prime} 39^{\prime \prime} \mathrm{E}$.

Description. Male. Body length: 3.35-4.2 mm.

Carapace: dark brown to red; granulated with uniform granules; slightly longer than wide; L/W 1.00-1.10; with 2 


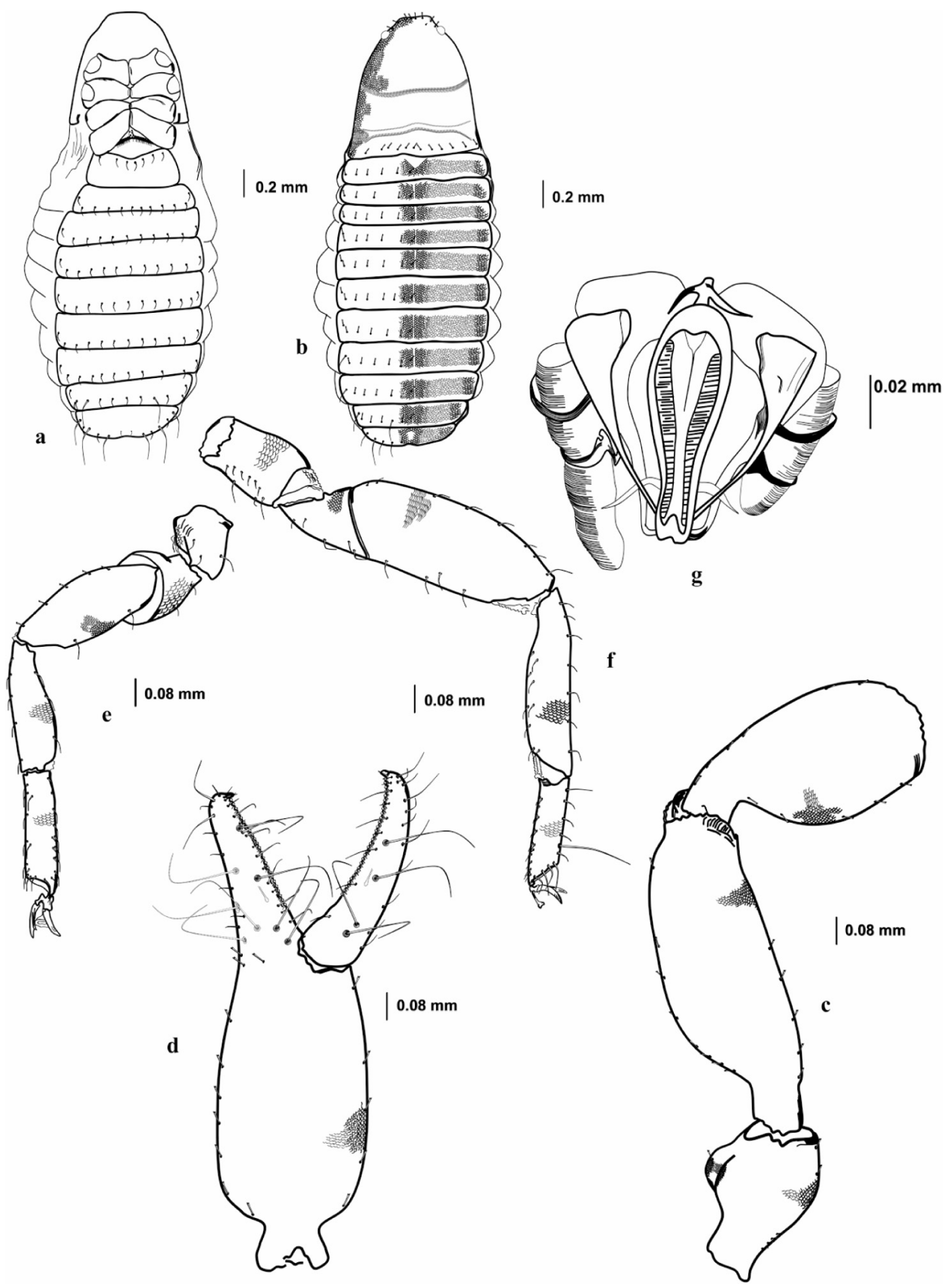

Fig. 1. Gobichelifer chelanops, male from Iran: a, body, ventral side; b, same, dorsal side; c, left pedipalp; d, right chela; e, leg I; f, leg IV; g, genital organ.

small corneal eyes; setae short with terminal denticulations; anterior margin with 6 and posterior margin with 13 setae; anterior margin with 2 very short setae in front of each eye and 4 long setae on border; 2 transverse furrow present (Fig. 1b), anterior furrow distinct, U-shaped and situated medially, narrow and extending to lateral margins; posterior furrow wider, shorter and straight.
Abdomen: with 11 segments.

Tergites (Fig. 1b): sclerotized and granulate; dark cream with 2 dark brown and extensive stripes, each half-tergite with a darker spot medially; tergites with setae arranged: 12 : 11: 13: 15: 14: 13: 15: 14: 13: 13: 12; most setae short with terminal denticulations; tergites I to III with serial setae (in one row), tergites IV to XI with one lateral seta on each 
half-tergite, tergites VIII-IX with longer lateral setae, tergite $\mathrm{X}$ with 2 long and simple setae on each half-tergite, longer seta situated medially, tergit XI with 6-8 simple setae, longest seta situated media-laterally; tergite I not divided, tergite II divided incompletely, tergite III to $\mathrm{X}$ divided completely, tergite XI not divided.

Sternites (Fig. 1a): with 10 segments; sternite I absent; sternites II-III deform and shaped anterior operculum and posterior operculum, anterior operculum with 34-35 and posterior operculum with $6^{-8}$ simple setae; sternites IV to $\mathrm{X}$ divided by narrow median line; sternite XI divided incompletely; sternal setae simple, narrow and slightly longer than tergal setae, sternite $\mathrm{X}$ with 2 simple and long setae on each half-sternite, longer seta situated medially, sternite XI with 4 pseudo-tactile and 2 tactile setae, shorter setae situated laterally, sternal setae arranged: 34: (0)6(0): (1)10(1): 11: 13: 12: 11: 13: 14: 10.

Pleurites: striated.

Chelicera: brown; galeal seta present; galea short with 23 terminal short rami; hand with 5 simple setae, basal and sub-basal setae shorter; fixed finger with 5 teeth, 2 terminal teeth small and 3 basal teeth large; rallum with 3 blades, distal blade longest with lateral denticulations; serrula exterior with 17-21 blades.

Pedipalp (Fig. 1c, d): dark red, darker than carapace; trochanter, femur, patella and chelal hand granulate; trochanter with 2 distinct dorsal ridges; trochanter $\mathrm{L} / \mathrm{W}$ 1.50-1.76; femur with distinct pedicel; retrolateral margin of femur curved posteriorly and prolateral margin straight with terminal pit; femur L/W 2.50-2.68; patella shaped like a club, with curved, distinct and narrow pedicel; retro lateral margin of patella slightly curved posteriorly and prolateral margin obviously curved anteriorly; patella L/W 2.02-2.08; chela stout and granulated with uniform granules; chela with distinct and moderate pedicel; chela (with pedicel) $\mathrm{L} / \mathrm{W}$ 2.92-3.05; chela (without pedicel) L/W 2.66-2.77; movable finger shorter than hand with pedicel, hand 1.33-1.40 longer than movable finger; fixed finger with 8 and movable finger with 4 trichobothria; fixed finger with trichobothrium ist situated posterior and it anterior to est, eb-esb-ib-isb aggregated basally; movable finger with trichobothrium st situated between $t$ and $s b, s b$ situated close to $b$; fixed finger with 31-32 and movable finger with 31-32 teeth; nodus ramosus long and present in both fingers, situated between $s b$ and $s t$ in movable finger and between est and et in fixed finger.

Leg I (Fig. 1e): stout and lighter in color than carapace; trochanter L/W 1.09-1.20; femur L/W 1.54-1.66; patella granulate laterally, L/W 2.47-2.63; tibia L/W 2.93-3.26; tarsus apparently shorter and narrower than tibia, terminal margin concave; L/W 3.36-3.54; basal setae short with terminal denticulations, sub-terminal setae simple; claws asymmetric, narrower claw with median accessory tooth; arolium short and wide.

Leg IV (Fig. 1F): very stout; lighter in color than carapace; coxa without coxal sac; trochanter L/W 1.30-1.60; femur L/W 1.45-1.68; patella wide and slightly granulate laterally, L/W 2.36-2.73; tibia slightly shorter than patella, prolateral margin curved anteriorly, L/W 3.73-4.11; tarsus apparently shorter than tibia, with 1 tactile setae posteriorly and 1 pseudo-tactile seta anteriorly, L/W 3.57-3.81; subterminal setae simple; claws symmetric and without accessory teeth; arolium short and wide.

Dimensions (L/W, in mm): Body: L 3.47. Carapace: 1.08/1.08. Chelicera: movable finger L 0.23. Pedipalp: trochanter $0.61 / 0.37$; femur $1.10 / 0.41$; patella $0.95 / 0.47$; chela (with pedicel) 1.65/0.54; chela (without pedicel) L 1.50; hand L 1.00; movable finger L 0.75. Leg I: trochanter $0.21 / 0.18$; femur $0.35 / 0.21$; patella $0.53 / 0.20$; tibia $0.46 / 0.15$; tarsus $0.39 / 0.11$. Leg $I V$ : trochanter $0.31 / 0.22$; femur $0.34 / 0.21$; patella $0.78 / 0.32$; tibia $0.75 / 0.19$; tarsus 0.42/0.11.

Female. Body length: 4.40-5.05 mm.

Carapace: brown to dark brown, distance between furrows darker and posterior margin lighter in color; granulated with uniform granules; longer than wide; L/W 1.08-1.09; with 2 small corneal eyes; setae short with terminal denticulations; anterior margin with 8 and posterior margin with 11 setae; anterior margin with 2 very short setae in front of each eye and 6 long setae on border; 2 transverse furrow present (Fig. 2b), anterior furrow distinct and $\mathrm{U}$ shaped, situated medially, narrow and extending to lateral margins; posterior furrow wider, shorter and straight.

Abdomen: with 11 segments.

Tergites (Fig. 2b): slightly sclerotized and granulate; cream with 2 brown or light brown and extensive stripes, each half-tergite with a darker spot medially; tergites with setae arranged: 13: 12: 12: 14: 14: 12: 15: 14: 12: 12: 12. most setae short with terminal denticulations; tergites I to II with serial setae (in one row), tergites III to XI with one lateral seta on each half-tergite, tergites VIII-IX with longer lateral setae, tergite $\mathrm{X}$ with 1 long and simple seta laterally on each half-tergite, tergite XI with 2 simple setae situated media-laterally; tergite I not divided, tergite II divided incompletely, tergite III to X divided completely, tergite XI not divided.

Sternites (Fig. 2A): with 10 segments; sternite I absent; sternites II-III deform and shaped anterior operculum and posterior operculum, anterior operculum with 21 and posterior operculum with 8 simple setae; pair genital cribriform plates present (Fig. 2c); sternites IV to $\mathrm{X}$ divided by narrow median line; sternite XI divided incompletely; sternal setae simple, narrow and slightly longer than tergal setae, sternite $\mathrm{X}$ and XI with 1 simple and long seta situated laterally on each half-sternite, sternal setae arranged: 21: $(0) 8(0)$ : (1)8(1): 12: 12: 12:13:14: 13: 12 .

Pleurites: striated.

Chelicera: brown; movable finger darker; galeal seta present; galea short with 4 terminal rami; hand with 5 simple setae, basal and sub-basal setae shorter; fixed finger with 5 teeth, 2 terminal teeth small and 3 basal teeth large; rallum with 3 blades, distal blade longest with lateral denticula- 


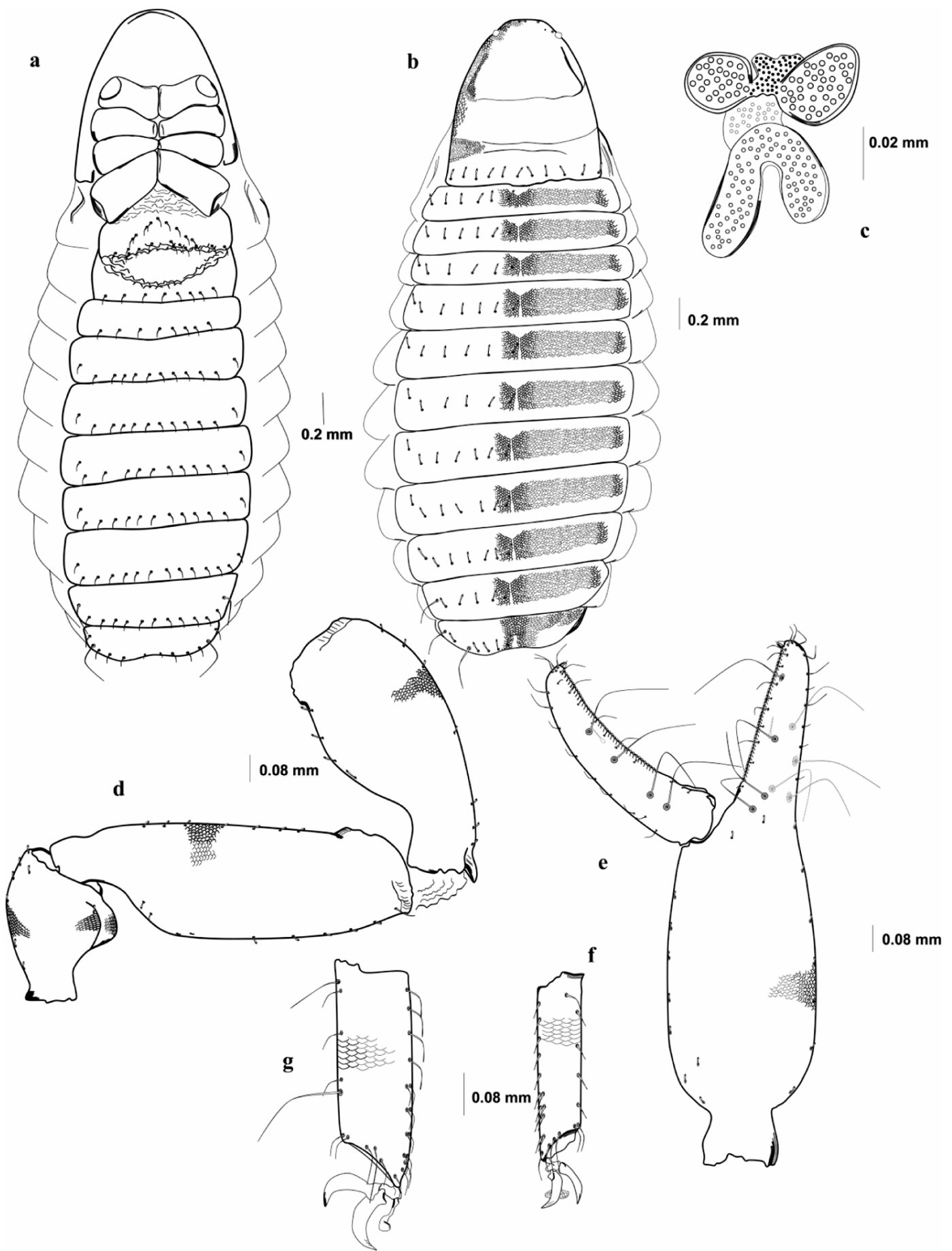

Fig. 2. Gobichelifer chelanops, female: a, body, ventral side; b, same, dorsal side; c, genital organ; d, right pedipalp; e, left chela; f, tarsus of leg I; g, tarsus of leg IV.

tions; serrula exterior with 20 blades.

Pedipalp (Fig. 2d, e): red, lateral margin black and very darker than carapace; trochanter, femur, patella and chelal hand granulate; trochanter with 2 distinct dorsal ridges; trochanter L/W 1.62-1.71; femur with distinct pedicel; retrolateral margin of femur curved posteriorly and prolateral margin straight with terminal pit; femur L/W 2.49-2.87; patella shaped like a club, with curved, distinct and narrow pedicel; retrolateral margin of patella slightly curved posteriorly and prolateral margin obviously curved anteriorly; patella L/W 2.00-2.25; chela stout and granulated with uniform granules; chela with distinct and moderate pedicel; chela (with pedicel) L/W 3.21-3.27; chela (without pedicel) L/W 2.94; movable finger shorter than hand with pedicel, hand 1.34-1.37 longer than movable finger; fixed finger with 8 and movable finger with 4 
trichobothria; fixed finger with trichobothrium ist situated posterior and it anterior to est, it situated close to ist than et, $e b-e s b-i b-i s b$ aggregated basally; movable finger with trichobothrium st situated close to $t$ than $s b, s b$ situated close to $b$; fixed finger with $30^{-34}$ and movable finger with 30-34 teeth; nodus ramosus long and present in both fingers, situated between $s b$ and $s t$ in movable finger and between est and it in fixed finger.

Leg I: stout and lighter in color than carapace; trochanter L/W 1.15; femur L/W 1.54-1.58; patella granulate laterally, L/W 2.5-3.09; tibia granulate laterally, L/W 3.20-3.57; tarsus (Fig. 2f) shorter and narrower than tibia, terminal margin concave; L/W 4.00-4.20; basal setae short with terminal denticulations, sub-terminal setae simple; claws symmetric, without accessory teeth; arolium short and slightly narrow.

Leg $I V$ : very stout; lighter in color than carapace; coxa without coxal sac; trochanter L/W 1.21; femur L/W 1.421.60; patella wide and slightly granulate laterally, L/W 2.36-2.67; tibia slightly shorter than patella, prolateral margin curved anteriorly, L/W 4.05; tarsus (Fig. 2g) apparently shorter and narrower than tibia, with 1 tactile setae posteriorly and 1 pseudo-tactile seta anteriorly, L/W 3.843.92; sub-terminal setae simple; claws symmetric and without accessory teeth; arolium short and narrow.

Dimensions (L/W, in mm): Body: L 4.40. Carapace: 1.25/1.15. Chelicera: movable finger L 0.26. Pedipalp: trochanter $0.57 / 0.35$; femur $1.15 / 0.40$; patella $0.99 / 0.44$; chela (with pedicel) 1.80/0.56; chela (without pedicel) L 1.62; hand L 1.07; movable finger L 0.80. Leg I: trochanter $0.23 / 0.20$; femur $0.37 / 0.24$; patella $0.65 / 0.21$; tibia $0.48 / 0.15$; tarsus $0.42 / 0.10$. Leg $I V$ : trochanter $0.34 / 0.28$; femur $0.37 / 0.26$; patella $0.92 / 0.39$; tibia $0.81 / 0.20$; tarsus $0.51 / 0.13$.

\section{Discussion}

The genus Gobichelifer resembles the genus Rhacochelifer in many ways including the stout pedipalpal segments, but Gobichelifer is easily distinguished by the absence of coxal sac in males (Krumpál 1979, see also Fig. 1a). Both genera are members of the tribe Dactylocheliferini (Beier 1932).

Gobichelifer currently includes a single species, $G$. chelanops (Redikorzev 1922) (type locality Sussa-myr River, Kirghiz Range, Kyrgyzstan), and two junior synonyms, Chelifer semenovi Redikorzev 1934 (type locality Sutushar Uzbekistan), and G. dashdorzhi Krumpál 1979 (type locality Oasis Echiin gol, Mongolia). The synonymies were suggested by Schwaller (1986, 1989). Gobichelifer chelanops has also been reported from Pakistan, Uzbekistan and Tajikistan (Dashdamirov \& Schawaller 1995, Harvey 2011). The newly collected specimens from Iran display some differences to previously recorded material. They are slightly smaller, for example the pedipalpal femur is $1.10 / 0.41$ (ð), $1.15 / 0.40 \mathrm{~mm}$ (우), and the chela (with pedicel) is $1.65 / 0.54$ (ð), 1.80/0.56 (우).

The femur of Gobichelifer dashdorzhi is 1.26-1.31/0.36-
0.39 (Ј), 1.25-1.46 $\mathrm{mm}$ (우) and the chela (with pedicel) is $1.92-2.01 / 0.59-0.63 \quad$ (Ј), $2.03-2.15 / 0.62-0.65 \mathrm{~mm}$ (우) (Krumpál 1979). The femur of Gobichelifer chelanops is $1.29 / 0.58 \mathrm{~mm}$ (ふ), and chela is $1.89 / 0.64 \mathrm{~mm}$ (ふ) (Dashdamirov \& Schawaller 1995).

The femur of $G$. dashdorzhi is more slender $[3.37 \times$ as long as wide (ð), $3.23-3.28 \times$ (우)] than G. chelanops $[2.22$

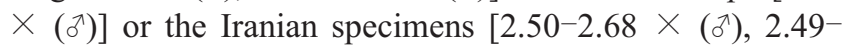
$2.87 \times($ 우)]. Similar discrepancies can be observed in the other pedipalpal segments (Krumpál 1979, Dashdamirov \& Schawaller 1995).

Another observable difference is the ratio of male tarsus I. Tarsus I of $G$. dashdorzhi is thinner $(4.67-5.25 \times)$, while $G$. chelanops is thicker $(3.00 \times)$ and the Iranian specimens are intermediate $(3.36-3.54 \times)$. Despite some observable differences between the Iranian populations and those from Central Asia and Mongolia, there is little evidence that they represent different species. We therefore attribute the Iranian material to $G$. chelanops with represents the first record of genus Gobichelifer from Iran.

The specimens were found living gregariously under the bark of various different tree species where they produced silk chambers. Gobichelifer chelanops has also been found under tree bark, including Populus (Krumpál 1979), and Ulmus, Salix, Juglans and Juniperus (Dashdamirov \& Schawaller 1995). The Iranian specimens were collected from the under bark of Elaeagnus and Platus trees.

\section{Acknowledgments}

The authors are grateful to vice chancellor of Research and the Faculty of Agriculture at Shahid Bahonar University of Kerman, Iran for their support of this research, and Dr. Christoph Höerweg who assisted us in Pseudoscorpions recognition, and very thankful to Professor Mark S. Harvey for his useful favors in Pseudoscorpions identification. We wish to thank Mr. Mahmoud Nassirkhani for his assistance.

\section{References}

Beier, M. 1932. Zur Kenntnis der Cheliferidae (Pseudoscorpionidea). Zool. Anz., 100: 53-67.

Beier, M. 1951. Ergebnisse der österreichischen Iran-Expedition 1949/50, Pseudoscorpione und Mantiden. Ann. Naturhistor. Mus. Wien, 58: 96-101.

Beier, M. 1971. Pseudoscorpione aus dem Iran. Ann. Naturhistor. Mus. Wien, 75: 357-366.

Beron, P. 2000. Non-insect Arthropoda (Isopoda, Arachnida and Myriapoda) on the high mountains of tropical Africa. Bonner Zool Monograph., 46: 153-188.

Beron, P. 2002. On the high altitude pseudoscorpions (Arachnida: Pseudoscorpionida) in the Old World. Hist. Nat. Bulg., 14: 29-44.

Caporicacco, L. di 1935. Arachnidi dell'Himalaia e de Karakoram. Mem. Soc. Ent. Ital., 13: 113-160, 161-263.

Dashdamirov, S. \& Schawaller, W. 1995. Pseudoscorpions from Middle Asia, Part 4 (Arachnida: Pseudoscorpiones). Stuttgarter Beitr. Naturk. Ser. A, 522(24): 21-22.

Harvey, M. S. 2011. Pseudoscorpions of the World, version 2.0 Western Australian museum. Online at: http://www. museum.wa.gov.au/arachnids/pseudoscorpions (viewed 21 Jun. 2011)

Krumpál, M. 1979. Gobichelifer dashdorzhi (Pseudoscorpionidea, Cheliferidae) eine neue gattung und species aus der Mongolei. 
Biologia, 34: 667-672.

Okáli, I. 1988. List of the type specimens in the collections of the Slovak National Museum - Institute of Natural History, Bratislava: Arachnida, Pseudoscorpionidea. Zbornik Slovenskeho Národneho Múzea Prirodovedny, 34: 223-226.

Redikorzev, V. 1918. Pseudoscorpiones nouveaux. I. Ezhegodnik Zoologicheskago Muzeya, 22: 91-101.

Redikorzev, V. 1922. Pseudoscorpiones nouveaux. II. Ezhegodnik Zoologicheskago Muzeya, 23: 257-272.

Redikorzev, V. 1934. Neue paläarktische Pseudoscorpione. Zoologische Jahrbücher, Abteilung für Systematik, Ökologie und Geographie der Tiere, 65: 423-440.

Redikorzev, V. 1949. Pseudoscorpions of Middle Asia, Tzudy. Zool. Inst. Acad. Nauk., 8: 643-644.

Roewer, C. F. 1936. Chelonethi oder Pseudoskorpione. In: Bronns,
H. G. (ed.) Bronn's Klassen und Ordnungen des Tierreichs, vol. 5(IV) 6(1), 160 pp. Akademische Verlagsgesellschaft M. B. H.: Leipzig.

Schawaller, W. 1986. Pseudoskorpione aus der Soqjetunion, Teil 2 (Arachnida: Pseudoscorpiones). Stuttgarter Beitr. Naturk., Ser. A, 396: 1-15.

Schawaller, W. 1989. Pseudoskorpione aus der Soqjetunion, Teil 3 (Arachnida: Pseudoscorpiones). Stuttgarter Beitr. Naturk., Ser. A, 440: 1-30.

Schawaller, W. 1995. Review of the pseudoscorpion fauna of the Far East of Russia (Arachnida Pseudoscorpionida). Arthropoda Selecta, 3: $123-126$.

Received December 25, 2012 / Accepted February 2, 2013 